\title{
Mechanical Properties of Lateritic Soil Reinforced with Geotextile Material (Nigerian Bagco Super Sack)
}

\author{
Kayode-Ojo, Ngozi* $\quad$ Akpoghene, Daniel Ihimekpen Ngozi Isioma \\ Department of Civil Engineering, Faculty of Engineering, University of Benin, Benin city, Edo State, Nigeria
}

\begin{abstract}
Due to the effect of urbanization and industrialization, soil improvement has been an area of major concern in the field of construction. Consequently, the modification of soil mechanical properties with invasive methods (e.g., sand drainages, piles, partial compensation techniques, etc.) or reinforcement techniques (e.g., geotextiles, geogrids, fibers, etc.) is becoming increasingly common. This research was to ascertain the mechanical properties of lateritic soil reinforced with locally available geotextile material in Nigeria (bagco supper sack). Soil samples were collected and their index and strength properties including; moisture content, particle size distribution, specific gravity, Atterberg limits, compaction and California Bearing Ratio were carried out. The samples were singly reinforced and also doubly reinforced with the Bagco Supper Sack Bag. Compaction and CBR tests were conducted on the reinforced soil. From the result, the soil can be classified as A-7-6 which is an inorganic clayey soil of very low to medium plasticity with a general subgrade rating of fair to poor according to AASHTO classification. The compaction test results showed an increase in the Maximum Dry Density and a corresponding decrease in Optimum Moisture Content when it was doubly reinforced and no increase when it was singly reinforced. The MDD increased from the average of $1.92 \mathrm{~g} / \mathrm{cm}^{3}$ for the control sample to $2.0 \mathrm{~g} / \mathrm{cm}^{3}$ for the doubly reinforced. While for the simply reinforced, there was a decrease in the MDD. The CBR results showed a gradual increase for singly reinforced soil and a rapid increase when they were doubly reinforced. This showed that Nigerian Bagco Supper Sack Bag can be used as soil reinforcement especially when doubly reinforced.
\end{abstract}

Keywords: Geosynthetics, geotextiles, reinforced soil, California Bearing Ratio, Maximum Dry Density, Optimum Moisture Content, Bagco Super Sack

DOI: $10.7176 / \mathrm{CER} / 12-2-09$

Publication date: February $29^{\text {th }} 2020$

\section{Introduction}

Due to urbanization and industrialization, soil improvement and stabilization has been an area of major concern in the field of construction. In particular, improvement in sub-grade in the construction of highway has always been an active area of study. The behaviour of soil reinforced with geosynthetics has gained wide acceptance over the last decades and it has been established that geo-synthetic reinforced soil greatly improves the overall engineering performance of the soil (Haldanker et al., 2017).

A geosynthetic has been defined by the "American Society for Testing and Materials (ASTM) committee D35 on Geo-synthetics" as " a planar product manufactured from polymeric material used with soil, rock, earth or other geotechnical engineering related material as an integral part of a man-made project structure, or system" (Parilda, 2011; Berg, 2007). It refers to all fabricated synthetic (usually polymeric) materials used in various geotechnical applications such as drainage, reinforcement, erosion control, and light weight fill (BMPR, 2005).

There are significant number of geosynthetic types and geosynthetic applications in the construction world. Thousands of years before, inclusions of different sorts of materials mixed with soil have been used. They were used in Roman construction to stabilize road ways and their edges. These early attempts were made of natural fibers, fabrics or vegetation mixed with soil to improve road quality (Sangeetha et al., 2018). A fundamental problem with using natural materials (wood, cotton, etc.) in buried environment is the biodegradation that occur from microorganisms in the soil. To overcome the limitations civil engineers searched for alternate solutions, one such alternative which has emerged as a popular material / technique in recent years is geotextiles and related products now commonly described as geosynthetics (Sangeetha et al, 2018).

When subjected to vertical loads, a reinforced soil mass typically exhibits higher load carrying capacity than the soil mass without reinforcement at Maximum Dry Density (MDD) and Optimum Moisture Content (OMC) of soil. Therefore the purpose of this research was to ascertain the mechanical properties of lateritic soil reinforced with locally available geotextile material (Nigerian Bagco Supper Sack). The specific objectives were to 1) Conduct geotechnical investigation on the soil and carry out laboratory identification assessments. 2) Carryout compaction test on both the reinforced (with locally available geo-synthetic material) and unreinforced lateritic soil using standard proctor method. 3) Carryout CBR test on both the unreinforced and reinforced lateritic soil. Related works on the performance of geosynthetics as reinforcing materialhave bee carried out (Ogundare et al, 2018; Ige, 2009; Charles et al, 2015; Amin and Hamid, 2011; Mehrad and Reza, 2011; Haldacker et al, 2017). The geosynthetic material selected for this test is not hazardous to the environment, is easily available and less expensive. The use of geosynthetics as reinforcement to enhance the compaction characteristics of weak lateritic 
soils could prove very beneficial in reducing the volume of borrow materials rejected for being marginal in quality.

Polypropylene granules, Bagco's major raw material are exuded into a cast film which is then slit into individual tapes, stretched to give orientation strength, and then wound on precision winders.

The next step is weaving of these tapes where fabric is woven in the form of a continuous tube. This weaving method has great advantages over sacks produced by flat looms. Bagco uses the revolutionary high-speed circular weaving process is that side seams, which constitute a major weakness in conventional sacks (because they break open easily), have been completely eliminated.

Also, this method of weaving gives a maximum cloth cover with minimum materials. The final stage is sack production. The fabric is cut to specific length; the base of the sack is folded and then sewn. Sacks can be printed in two colour prints. The finished products are then baked (www.winne.com/nigeria2/co21.html).

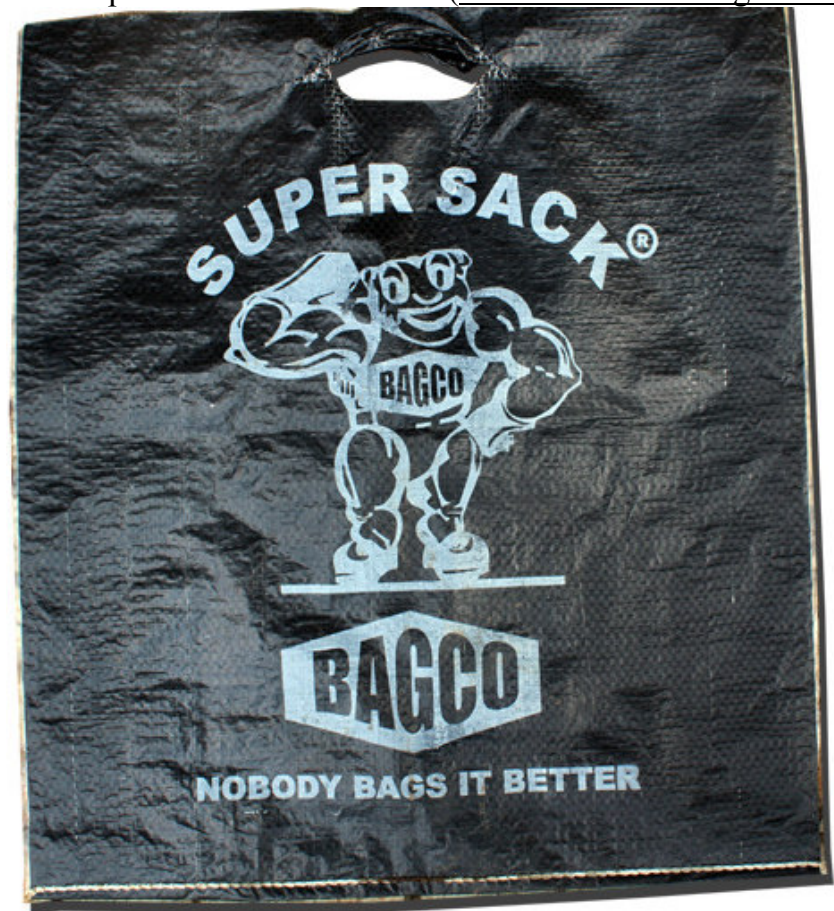

Figure 1: Nigerian Bagco Super Sack Bag

\section{Materials and Method}

\subsection{Materials and Location}

The materials used for this study include;

i. lateritic soil and

ii. Locally available geosynthetics (bagco supper sack).

The lateritic soil samples were obtained using the hand auger from two boreholes on the open field after the new Capitol Building at the University of Benin, Ugbowo campus in Benin City of Edo state. The University of Benin is located in Ovia North-East LGA which lies between Latitude $6^{\circ} 24^{\prime} 12.10^{\prime \prime}$ North of the equator and Longitude $5^{\circ} 37^{\prime} 01.97^{\prime \prime}$ East of the Greenwich Meridian.

The first soil sample collected was extracted at a depth of $1.5 \mathrm{~m}$ from a borehole location which lies between latitude $6^{\circ} 23^{\prime} 50.98^{\prime \prime}$ North of the equator and Longitude $5^{\circ} 38^{\prime} 10.78^{\prime \prime}$ East of the Greenwich Meridian, the second soil sample collected was extracted at a depth of $2 \mathrm{~m}$ from a borehole location which lies between latitude $6^{\circ} 23^{\prime} 47.73^{\prime \prime}$ North of the equator and Longitude $5^{\circ} 38^{\prime} 9.99^{\prime \prime}$ East of the Greenwich Meridian. Figure 2 shows the location of the samples collected.

Locally available geosynthetic material was obtained from Uselu Main Market, Benin, Edo State, Nigeria. The bagco super sack was cut into the mold shape and weighed. 


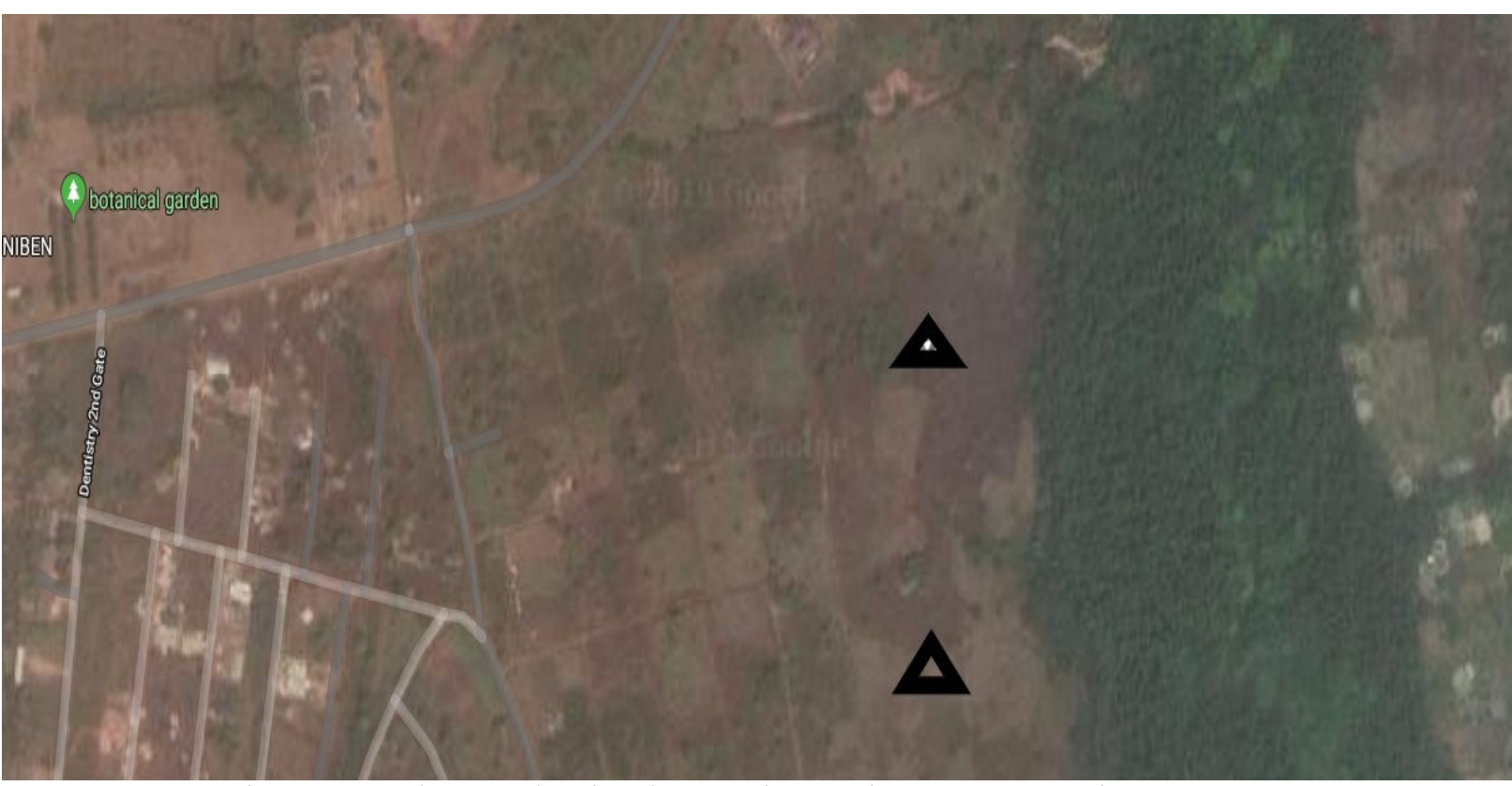

Figure 2 Google Map Showing the Sample Location Source: Googlemaps.com

\subsection{Soil Sampling and Laboratory Testing}

The soil samples were collected from two boreholes at depths of $1.5 \mathrm{~m}$ and $2 \mathrm{~m}$, respectively with the following investigations carried out in accordance with British Standard - BS 1377; 90; (Part 2, Section 3, 4, 5,6, 8, 9: Part 4, Section 3 and 7).

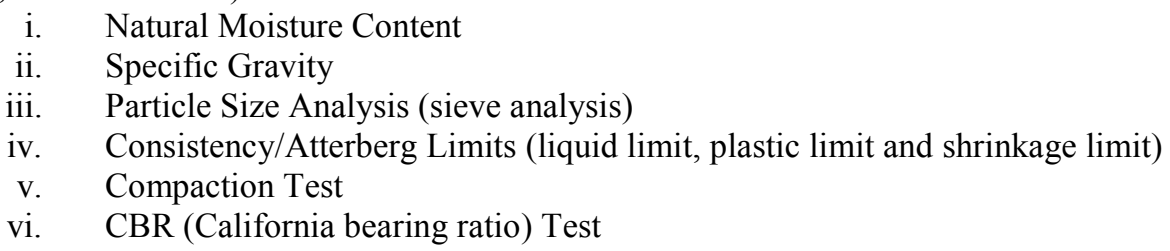

\section{Results and Discussion}

The mean results of the index properties of the unreinforced soil is shown in Table 1.

Table 1: Index Properties of Soil

\begin{tabular}{|c|c|c|}
\hline Samples & A & B \\
\hline Moisture content (\%) & 16.26 & 16.98 \\
\hline Specific Gravity & 2.36 & 2.41 \\
\hline Liquid Limit (\%) & 35.4 & 35.0 \\
\hline Plastic Limit (\%) & 21.6 & 23.3 \\
\hline Plasticity Index (\%) & 13.8 & 11.7 \\
\hline \% Passing through Sieve 200 & 63.3 & 59.8 \\
\hline UCSC Soil Classification & CL & CL \\
\hline AASHTO Soil Classification & A-7-6 & A-7-6 \\
\hline
\end{tabular}

The natural moisture content for Samples A and B has an average value of 16.26 and 16.98 respectively. The slight variation in moisture content is a function of the void ratios and the specific gravities of the sample. This showed that the soil samples contained appreciable amount of moisture which is largely affected by the climatic condition. The specific gravity for the soil samples ranged from 2.36-2.41. This range of values indicates that the soil is organic in nature and is weak in strength. As a result, such soils can only be used as a construction material when it is reinforced. The liquid limit ranged from $35.4-350 \%$, plastic limit from $21.6-23.3 \%$ and the plasticity index of the soil samples decreases from 13.8 to $11.7 \%$. This range of PI shows that the soil is a cohesive silty clay with a medium degree of plasticity. The results of the sieve analysis test showed that the percentage passing sieve 200 ranges from 63.3 to $59.8 \%$. This shows that there is a high percentage of clay in the soil samples which is well graded providing more grain to grain area contact.

The AASHTO classification for the tested soil is A-7-6 which is a clayey soil with a general subgrade rating of fair to poor. While the UCSC classification for the tested soil samples shows that the soils are inorganic clays of very low to medium plasticity.The results of the sieve analysis test showed that the percentage passing ranges 
from 63.3 to $59.8 \%$. This shows that there is a high percentage of clay in the soil samples which is well graded providing more grain to grain area contact.

\subsection{Compaction Test Results}

The summary of the compaction test result for the control sample, singly reinforced and doubley reinforced samples are shown in Table 2.

Table 2: Maximum dry density and Optimum moisture content for both reinforced and natural soil

\begin{tabular}{|c|c|c|c|c|c|c|c|c|}
\hline Samples & $\begin{array}{l}\text { A } \\
\text { Control }\end{array}$ & $\begin{array}{l}\text { B } \\
\text { Control }\end{array}$ & $\begin{array}{l}\text { A } \\
\text { Top } \\
\text { Singly } \\
\text { Reinforced }\end{array}$ & $\begin{array}{l}\text { B } \\
\text { Top } \\
\text { singly } \\
\text { Reinforced }\end{array}$ & $\begin{array}{l}\text { A } \\
\text { Bottom } \\
\text { singly } \\
\text { Reinforced }\end{array}$ & $\begin{array}{l}\text { B } \\
\text { Bottom } \\
\text { singly } \\
\text { Reinforced }\end{array}$ & $\begin{array}{l}\text { A } \\
\text { doubly } \\
\text { Reinforced }\end{array}$ & $\begin{array}{l}\text { B } \\
\text { doubly } \\
\text { Reinforced }\end{array}$ \\
\hline $\begin{array}{l}\text { MDD } \\
\left(\mathrm{g} / \mathrm{cm}^{3}\right)\end{array}$ & 1.96 & 1.88 & 1.87 & 1.73 & 1.85 & 1.49 & 2.22 & 1.78 \\
\hline $\begin{array}{l}\text { Avg } \\
\text { MDD } \\
\left(\mathrm{g} / \mathrm{cm}^{3}\right)\end{array}$ & \multicolumn{2}{|c|}{1.92} & \multicolumn{2}{|c|}{1.80} & \multicolumn{2}{|c|}{1.67} & \multicolumn{2}{|c|}{2.00} \\
\hline $\begin{array}{l}\text { OMC } \\
(\%)\end{array}$ & 14.6 & 15.06 & 18.3 & 19.98 & 19.80 & 27.6 & 13.00 & 19.00 \\
\hline $\begin{array}{l}\text { Avg } \\
\text { OMC } \\
(\%) \\
\end{array}$ & \multicolumn{2}{|c|}{14.83} & \multicolumn{2}{|c|}{19.14} & \multicolumn{2}{|c|}{23.70} & \multicolumn{2}{|c|}{16.00} \\
\hline
\end{tabular}

From Table 2, the average Optimum Moisture Contents (OMC) for the control soil sample is $14.83 \%$ with an average Maximum Dry Densities (MDD) of $1.92 \mathrm{~g} / \mathrm{cm}^{3}$. The singly reinforced soil sample showed a decrease in the average MDD when compared to the control sample. The range of this decrease is from 1.92 to $1.82 \mathrm{~g} / \mathrm{cm}^{3}$. The average OMC increased from $14.83 \%$ to $19.14 \%$. This increase in OMC is probably due to the additional water held within the flocculent soil structure due to the layers of bagco super sack at the top and bottom placements. However, it was observed that there was an increase in MDD from $1.92 \mathrm{~g} / \mathrm{cm}^{3}$ to $2.00 \mathrm{~g} / \mathrm{cm}^{3}$ while the average OMC also increased from 14.83 to $16.00 \%$ when the soil was doubly reinforced at the top and bottom. An increase in MDD is a general indication of soil improvement.

\subsection{California Bearing Ratio (CBR) Test Results}

Table 3 shows the summary of the California Bearing Ratio (CBR) test results.

Table 3: Summary of the CBR Results

\begin{tabular}{|c|c|c|c|c|c|c|c|c|}
\hline & \multicolumn{2}{|c|}{$\begin{array}{c}\text { Sample A } \\
\text { Unsoaked (\%) }\end{array}$} & \multicolumn{2}{|c|}{$\begin{array}{c}\text { Sample A } \\
\text { Soaked (\%) }\end{array}$} & $\begin{array}{c}\text { Sample B } \\
\text { Unsoaked (\%) }\end{array}$ & \multicolumn{3}{c|}{$\begin{array}{c}\text { Sample B } \\
\text { Soaked (\%) }\end{array}$} \\
\hline & $2.5 \mathrm{~mm}$ & $5.0 \mathrm{~mm}$ & $2.5 \mathrm{~mm}$ & $5.0 \mathrm{~mm}$ & $2.5 \mathrm{~mm}$ & $5.0 \mathrm{~mm}$ & $2.5 \mathrm{~mm}$ & $5.0 \mathrm{~mm}$ \\
\hline Natural Soil Unreinforced & 26 & 31 & 22 & 28 & 17 & 15 & 12 & 12 \\
\hline Singly Reinforced (top) & 28 & 31 & 24 & 34 & 23 & 32 & 22 & 32 \\
\hline Singly Reinforced (bottom) & 24 & 32 & 25 & 31 & 23 & 32 & 24 & 31 \\
\hline Doubly Reinforced (top \& bottom) & 28 & 36 & 28 & 36 & 28 & 35 & 29 & 35 \\
\hline
\end{tabular}

The results showed gradual increase in strength when the soil samples were singly reinforced at the top and bottom only. However, a rapid increase in the strength of soil is noted when they were doubly reinforced at the top and bottom.

\section{Conclusion}

From the compaction and CBR results obtained, the Nigerian Bagco Supper Sack Bag can be better used as soil reinforcement when doubly reinforced. It can therefore be concluded that bagco supper sack is an effective reinforcement for improving the geotechnical properties of lateritic soil samples.

\section{References}

AASHTO (1986) Standard for Transportation Materials and Methods of Sampling and Testing Fourteenth Edition, AASHTO: Washington, DC.

Amin C., Hamid N. (2011). CBR Test on Reinforced Clay, 2011 Pan-American CGS Geotechnical Conference. B.S.I., (1990); Methods of Test for Civil Engineering Purpose (British Standard Institution 1377:90).

Bellal H. Md., Zakaria H. Md., Toshinori S. (2012). Interaction Properties of Geosynthetic with Different Backfill Soils, International Journal of Geosciences, 2012, 3, 1033-1039.

Berg, R.R., and Suits, L.D., (2007); Geosynthetic Transportation in the New Millennium, Ryan Berg and Associates, New York.pp.1-2

BMPR, (2005); Pavement Technology Advisory-Geosynthetics. Illinois Department of Transportation, pp.1-2 
Charles, A. A., Ernest, A., Richter, O. (2015); Effect of Triaxial Geogrid Reinforcement on CBR Strength of Natural Gravel Soil for Road Pavements. Journal of Civil Engineering Research, Vol. 5(2), pp. 45-51..

Charman, J. H. (1988); Laterite in road pavements. London Construction Industry Research and Information Association Special Publication 47, CIRIA, London, 71pp. Domenico, P. A., and F. W Schwartz, 1990. Physical and Chemical Hydrogeology. New York, John Wiley and Sons, Elsevier, Amsterdam.

Georg, H., (2007). Improving the bearing capacity of soils with geosynthetics. Retrieved from www.geosynthetics.com.

Haldanker S., Shirodkar V and Devapa V.M (2017). Strength Characterization of Lateritic Soil with Geogrid Inclusion. International Journal of Engineering Research in Mechanical and Civil Engineering (IJERMCE), ISSN (Online) 2456-1290

Holtz, R.D. (2001): Geosynthetics for Soil Reinforcement, University of Washington.pp.1-7

McCarthy, David F. (2006). Essentials of soil mechanics and foundations: basic geotechnics (7th ed.). Upper Saddle River, New Jersey: Prentice Hall. ISBN 978-0-13-114560-3.

Ige, J.A, (2009). Laboratory study on geotextile reinforced soil for poor subgrade, International Journal of Engineering Technology Research \& Management (IJETRM), Vol 2, Issue 9.

Mehrad K., Reza Z. (2011). Influence of Geosynthetic Reinforcement on the Shear Strength Characteristics of Two-Layer Sub-Grade. Acta Geotechnica Slovenica, 2011/1

Ogundare, D.A ; Adebara, S.A; Familusi, A.O; Adewumi, B.E. (2018). Stabilization of subgrade using geosynthetics (case study- geotextile) under soaked condition, Annals of Faculty Engineering Hunedoara International Journal of Engineering, Vol 157, No 4.

Parilda, P. (2011); A Seminar on Geosynthetics. Unpublished.

Sangeetha, D.M., Naveen, D.T., Vishnu, K.B., Sethuja, B., Sachu, S.M., and Jeevan, K.V., (2018); Efficacy Of Geosynthetics In Stabilization Of Subgrade Soil. International Journal of Pure and Applied Mathematics, Vol 120 No. 62018 , pp. 6779-6797 